\title{
EVALUASI INPUT, PROSES, DAN HASIL MELALUI PENERAPAN MODEL PEMBELAJARAN LEARNING CYCLE
}

\author{
Susanti Faipri Selegi \\ Universitas PGRI Palembang \\ ( $\Xi$ )susantifaipriselegi@gmail.com
}

\begin{abstract}
ABSTRAK
Evaluasi bertujuan memberikan gambaran objektif pada mata kuliah evaluasi belajar Geografi dengan menerapkan konsep evaluasi input, proses, dan hasil. Selain itu, penelitian ini bertujuan untuk mengetahui evaluasi input, proses, dan hasil melalui penerapan model pembelajaran learning cycle. Jenis penelitian ini adalah penelitian evaluasi dengan pendekatan kuantitatif. Data diperoleh melalui teknik kuesioner dan tes. Adapun hasil penelitian ini menunjukkan bahwa evaluasi input, yang meliputi antusiasme, kedisiplinan, sarana dan prasarana, kesiapan tenaga pendidik, dan lingkungan dengan kategori sedang. Evaluasi proses, yang meliputi engagement (keterlibatan), expolaration, explanation, elaboration dan evaluation melalui model pembelajaran learning cycle dengan kategori baik. Evaluasi hasil, yang meliputi hasil terbaik pada mata kuliah evaluasi belajar Geografi, dan skor hasil belajar yang diperoleh >80 dengan kategori baik. Hasil tes belajar pada ujian akhir semester setelah diterapkannya model pembelajaran learning cycle dengan rata-rata 81,63 dan kategori penilaian tes pada kategori baik. Hasil pengujian secara simultan $\mathrm{X}_{1}$ evaluasi input, $\mathrm{X}_{2}$ evaluasi proses, $\mathrm{X}_{3}$ evalausi hasil, dan $\mathrm{Y}$ tes hasil belajar pada ujian akhir semester setelah diterapkannya model pembelajaran learning cycle, diperoleh nilai $F_{\text {hitung }}$ sebesar 4,272 dengan nilai probabilitas (sig.) $=0,012$ dan $F_{\text {tabel }}$ sebesar 2,86. Dengan demikian nilai $\mathrm{F}_{\text {hitung }}=4,272$ lebih besar dari $\mathrm{F}_{\text {tabel=2,86}}$ maka dapat disimpulkan bahwa varaibel $\mathrm{X}_{1}$ evaluasi input, $\mathrm{X}_{2}$ evaluasi proses, $\mathrm{X}_{3}$ evaluasi hasil secara simultan berpengaruh terhadap variabel terikat $\mathrm{Y}$ yaitu tes hasil belajar pada ujian akhir semester setelah diterapkannya model pembelajaran learning cycle.
\end{abstract}

Key Words : Evaluasi input, proses, hasil, learning cycle

\section{PENDAHULUAN}

Pembelajaran merupakan usaha sadar untuk membantu mahasiswa agar mereka dapat belajar sesuai dengan kebutuhan dan minatnya. Aunurrahman (2012:6-8) mengungkapkan bahwa pendidikan bertumpu pada 4 (empat) pilar, yaitu (1) learning to know, (2) learning to do, (3) learning to live together, dan (4) learning to be. Learning to know adalah upaya memahami instrumen-instrumen pengetahuan baik sebagai alat maupun sebagai tujuan. Sebagai alat, pengetahuan diharapkan akan memberikan kemampuan setiap orang untuk memahami berbagai aspek lingkungan agar mereka dapat hidup dengan harkat dan martabatnya dalam upaya mengembangkan keterampilan kerja dan berkomunikasi dengan baik. Learning to do lebih ditekankan bagaimana mengajarkan untuk memperaktikan segala sesuatu yang telah dipelajari dan dapat mengadaptasi pengetahuan yang telah diperolehnya dengan pekerjaan dimasa depan. Learning to live together mengajarkan, melatih dan membimbing peseta didik agar dapat menciptkan hubungan melalui komunikasi yang baik. Learning to be, prinsip dasar pendidikan hendaknya mampu memberikan konstribusi untuk perkembangan seutuhnya setiap orang, jiwa dan raga, intelegensi, kepekaan, rasa etika, tanggung jawab pribadi dan nilai-nilai spritual. Sehingga dapat berpikir kritis, mandiri dan mampu membuat keputusan sendiri.

Keempat pilar tersebut sekaligus merupakan misi dan tanggung jawab yang harus diemban oleh pendidikan melalui kegiatan belajar mengetahui, 
belajar berbuat, belajar hidup bersama dan belajar menjadi seseorang atau belajar menjadi diri sendiri, maka akan semakin luas wawasan seseorang tentang pengetahuan, tentang nilai-nilai positif, tentang orang lain serta tentang berbagai dinamika perubahan yang terjadi. Berdasarkan konsep tersebut, hakikat pembelajaran dan belajar menjadi suatu hal yang penting dalam mewujudkan pendidikan yang berkualitas. Keberhasilan dalam pembelajaran dipengaruhi oleh materi yang diajarkan, kualitas mengajar, sarana prasarana, minat dan keseriusan mahasiswa. Untuk mengetahui ketercapaian pembelajaran maka diperlukan evaluasi pembelajaran. Evaluasi merupakan suatu proses atau kegiatan pemilihan, pengumpulan, analisis dan penyajian informasi yang dapat digunakan sebagai dasar pengambilan keputusan. Evaluasi pembelajaran yang dilaksanakan dengan baik dapat membantu upayaupaya dalam rangka menyempurnakan jalannya program pembelajaran sehingga lebih efektif (Widoyoko, 2009:13).

Berdasarkan pengamatan dalam proses pembelajaran ada beberapa kendala yang dihadapi, antara lain; mahasiswa sibuk dengan aktivitasnya sendiri, seperti ngobrol dengan temannya, sibuk dengan dawainya, tidak siap mengikuti pelajaran dibuktikan dengan tidak lengkapnya perlengkapan belajar. Hal tersebut menyebabkan mahasiswa tidak fokus pada materi sehingga menjadi kurang antusias mengikuti pelajaran. Salah satu cara yang dapat digunakan agar masalah tersebut tidak terjadi, maka diperlukan model pembelajaran yang tepat dan efektif. Model pembelajaran yang digunakan dalam proses belajar mengajar memiliki peranan penting dalam menentukan keberhasilan dalam belajar. Oleh karena itu, dengan menerapkan model pembelajaran efektif dan efesien diharapkan dapat meningkatkan partisipasi mahasiswa dalam kegiatan belajar mengajar yang lebih kondusif dengan lebih melibatkan aspekaspek kecerdasan.

Penerapan model learning cycle dalam mata kuliah evaluasi belajar Geografi akan memudahkan mahasiswa dalam memperoleh dan memahami konsep. Selain itu, model ini dirasakan cukup relevan karena melalui learning cycle lebih menantang dan dapat meningkatkan partisipasi aktif mahasiswa pada pembelajaran dikelas. Berdasarkan permasalahan di atas, maka peneliti ingin melakukan kajian lebih lanjut dengan judul 'Evaluasi input, proses, dan hasil melalui penerapan model pembelajaran learning cycle' Adapun rumusan masalah dalam penelitian ini adalah bagaimana evaluasi input, proses, dan hasil melalui penerapan model pembelajaran learning cycle? dengan tujuan untuk mengetahui evaluasi input, proses, dan hasil melalui model pembelajaran learning cycle.

Learning Cycle merupakan suatu model pembelajaran yang berpusat pada mahasiswa serta didasarkan pada pandangan kontruktivisme yaitu: (1) pengetahuan dikonstruksi dari pengalaman siswa, (2) informasi baru yang dimiliki siswa berasal dari interpretasi individu, (3) orientasi pembelajaran adalah investigasi dan penemuan yang merupakan pemecahan masalah. Pada mulanya model ini terdiri dari tiga tahap, yaitu exploration, concept introduction dan concept aplication.

Tiga tahap tersebut saat ini berkembang menjadi lima tahap yang terdiri atas engagement, exploration, explanation, elaboration serta evaluation. Learning Cycle dengan lima tahap ini dikenal dengan Learning Cycle 5E. Selain itu, learning cycle 5E merupakan model pembelajaran yang berpusat pada peserta didik (student centered), berupa rangkaian tahap-tahap kegiatan (fase) yang diorganisasi sedemikian rupa, meliputi pembangkitan minat (engagement), eksplorasi (exploration), penjelasan (explanation), elaborasi (elaboration), dan evaluasi (evaluation) sehingga peserta didik dapat menguasai kompetensikompetensi yang harus dicapai dalam pembelajaran dengan jalan berperan aktif. Aktivitas dalam pembelajaran Learning cycle lebih banyak ditentukan oleh peserta didik sehingga peserta didik menjadi lebih aktif (Septiana, dkk 2006). Untuk mengetahui suatu model pembelajaran memiliki pengaruh atau tidak maka diperlukan evaluasi. Seperti yang dikatakan oleh Mertens (2010:49) : "Evaluation is an applied inquiry process for collecting and synthesizing evidence that ions about the state of affairs, value, 
merit, wort, significance, or quality of a program, product, person, policy, proposal, or plan”.

Evaluasi adalah proses penerapan yang dilakukan untuk mengumpulkan dan mensisntesiskan pembuktian sebagai kesimpulan tentang kualitas program, produk, orang, kebijakan, proposal, atau perencanaan. Pengertian tersebut menunjukkan bahwa evaluasi tidak hanya membahas tentang pendidikan akan tetapi dapat mengakaji seluruh aspek. Lebih lanjut, Weiss dalam Widyoko (2009:5) menyatakan tujuan evaluasi adalah: "The purpose of evaluation research is to measure the effect of program agains the goals it set out accomplish as a means of constributing to subsuquest decision making about the program and improving future programming."

Ada empat hal yang ditekankan pada rumusan tersebut, yaitu (1) menunjuk pada penggunaan metode penelitian, (2) menekankan pada hasil suatu program, (3) penggunaan kriteria untuk menilai, (4) konstribusi terhadap pengambilan keputusan dan perbaikan program dimasa mendatang. Widoyoko (2009:15) keberhasilan suatu pembelajaran tidak dapat terlepas dari segi pelaksanaannya, maka evaluasi menyangkut berbagai hal yang terkait kualitas masukan, kualitas proses, maupun kualitas hasil pembelajaran.

Hasil belajar mempunyai hubungan yang erat dengan belajar yaitu untuk mengetahui sampai dimana perubahan yang terjadi pada diri seseorang, baik perubahan tingkah laku dan kecakapan yang yang dapat dilihat dari hasil belajarnya. Tujuan pendidikan yang ingin dicapai berdasarkan hasil belajar secara umum dapat diklasifikasikan menjadi tiga bagian yaitu bidang kognitif (penguasaan intelektual), bidang efektif (berhubungan dengan sikap dan nilai), serta bidang psikomotorik (kemampuan atau keterampilan) (Dimyati \& Mudjiono, 2009:201). Dengan demikian, hasil belajar adalah adanya perubahan tingkat kemampuan mahasiswa setelah mengikuti pelajaran selama kurun waktu yang tertentu. kemampuan-kemampuan tersebut mencakup aspek kognitif, afektif, dan psikomotorik, selain itu hasil belajar dapat dilihat melalui kegiatan evaluasi yang bertujuan untuk mendapatkan data pembuktian yang akan menunjukkan tingkat kemampuan dalam mencapai tujuan pembelajaran.

\section{METODOLOGI PENELITIAN}

Jenis penelitian ini dikategorikan sebagai penelitian evaluasi. Penelitian evaluasi merupakan kegiatan penelitian untuk mengumpulkan data, menyajikan informasi yang akurat dan objektif mengenai evaluasi pembelajaran. Peneliti berusaha menggambarkan evaluasi input, proses, dan hasil melalui penerapan model pembelajaran learning cycle. Oleh karena itu, penelitian ini adalah penelitian evaluasi yang bertujuan untuk memperbaiki proses pembelajaran dan menentukan tingkat keberhasilan mahasiswa.

Pendekatan yang digunakan dalam penelitian ini adalah pendekatan kuantitatif. pendekatan ini digunakan sebagai pertimbangan bahwa gejala penelitian merupakan proses yang dilakukan melalui kajian terhadap perilaku atau aktivitas para pelaku yang terlibat didalamnya. Fraenkel and Wallen (2009:15) mengatakan: "Quantitave research usually base their work on the belief that facts and feeling can be separated, that the world is a single reality made up of facts that can be discovered".

Pernyataan tersebut menjelaskan bahwa penelitian kuantitatif biasanya didasarkan pada fakta-fakta yang dapat ditemukan. Lebih lanjut, Margono (2009:105) mengatakan bahwa penelitian kuantitatif adalah suatu proses menemukan pengetahuan yang menggunakan data berupa angka sebagai alat menemukan keterangan mengenai apa yang ingin kita ketahui. Sedangkan penelitian deskriptif dimaksudkan memberikan ciri-ciri orang tertentu, kelompok atau keadaan. Penelitian ini dilaksanakan pada Program Studi Pendidikan Geografi Universitas PGRI Palembang. Adapun waktu pelaksanaan semester ganjil tahun akademik 2017/2018.

Menurut Sugiyono (2009:61) populasi adalah wilayah generalisasi yang terdiri atas: obyek/subjek yang mempunyai kualitas dan karakteristik tertentu yang ditetapkan oleh peneliti untuk dipelajari dan kemudian ditarik 
kesimpulannya. Populasi bukan sekedar jumlah yang ada pada objek/subjek yang dipelajari, tetapi meliputi seluruh karakteristik/sifat yang dimiliki oleh subjek aau objek yang diteliti. Populasi dalam penelitian ini adalah mahasiswa semester 5 tahun akademik 2017/2018. Untuk itu sampel yang diambil dari populasi harus betul-betul representative (mewakili). Oleh karena itu, penelitian ini menggunakan purposive sampling yang didasarkan atas ciri-ciri tertentu atau kriteriakriteria tertentu yang diterapkan berdasarkan tujuan penelitian sampel terdiri dari 38 mahasiswa program studi pendidikan Geografi Universitas PGRI Palembang.

Sedangkan variabel dalam penelitian menurut Sugiyono (2009:2), adalah segala sesuatu yang berbentuk apa saja yang ditetapkan oleh peneliti untuk dipelajari sehingga diperoleh informasi tentang hal tersebut, kemudian ditarik kesimpulannya. Variabel dalam penelitian ini, terdiri dari variabel bebas yaitu evaluasi input (X1), proses (X2), hasil pembelajaran (X3) dan variabel terikat $(\mathrm{Y})$ tes hasil belajar pada ujian akhir semester setelah diterapkannya model pembelajaran learning cycle.

Penelitian ini menggunakan metode eksperimen. Slavin dalam Mertens (2010:123) mengatakan "the experiment is the design of choice for studies that seek to make causal conclusion, and particularly evaluations of education innovations." Sedangkan desain yang digunakan adalah posttest-only control group. Menurut Mertens (2010:135) "The posttest-only control group design is similar to the pretestposttest control group design except that no pretest is given.". Posttest-only control group dalam penelitian ini dilaksanakan setelah diterapkannya model pembelajaran learning cycle.

Teknik pengumpulan data dalam penelitian ini menggunakan beberapa cara, yaitu: kuesioner/angket dan tes. Margono (2009:167168) kuesioner ialah suatu alat pengumpul informasi dengan cara menyampikan sejumlah pertanyaan tertulis untuk menjawab secara tertulis oleh responden. Kuesioner yang digunakan dalam penelitian ini adalah kuesioner berstruktur atau disebut juga kuesioner tertutup, berisi pertanyaan- pertanyaan yang disertai sejumlah alternatif jawaban yang disediakan. Kuesioner yang dimaksud dalam penelitian ini adalah evaluasi input, proses, dan hasil pembelajaran. Sementara itu, tes ialah seperangkat rangsangan (stimuli) yang diberikan kepada seseorang dengan maksud untuk mendapat jawaban yang dapat dijadikan dasar bagi penetapan skor angka. Tes yang digunakan dalam penelitian ini adalah tes tertulis. Tes tertulis yaitu berupa sejumlah pertanyaan yang diajukan secara tertulis tentang aspek-aspek yang ingin diketahui keadaannya dari jawaban yang diberikan secara tertulis Tes tertulis yang dimaksud adalah tes esai, yaitu tes yang menghendaki agar testee memberikan jawaban dalam bentuk uraian atau kalimat-kalimat yang disusun sendiri (Margono, 2009:170). Tes yang dimaksud dalam penelitian ini adalah tes pada ujian akhir semester.

Evaluasi ini bertujuan memberikan gambaran objektif pada mata kuliah evaluasi belajar Geografi dengan menerapkan konsep evaluasi input, proses, dan hasil. Teknik analisis data yang digunakan adalah analisis deskriptif kuantitatif, yaitu mendeskripsikan dan memaknai data tiaptiap komponen evaluasi kemudian disesuaikan acuan kriteria yang telah ditentukan. Sementara itu, data kuantitatif diperoleh dari tes hasil belajar mahasiswa, sedangkan kuesioner menggunakan teknik penskoran (skala likert).

Adapun langkah-langkah yang digunakan dalam menganalisis data yang telah dikumpulkan melalui instrumen kuesioner adalah; (1) penskoran jawaban responden, (2) menjumlahkan skor total masing-masing responden, (3) mengelompokkan skor responden berdasarkan tingkat kecenderungannya. Kemudian dilanjutkan dengan uji persyaratan analisis, yaitu uji normalitas, uji linearitas, dan uji hipotesis analisis regresi linear berganda.

Analisis regresi digunakan untuk mengetahui pengaruh variabel bebas atau prediktor (X) terhadap variabel terikat atau kriterium $(\mathrm{Y})$. Selain itu, regresi linear ganda pada penelitian ini digunakan untuk mengetahui pengaruh evaluasi input $\left(\mathrm{X}_{1}\right)$, proses $\left(\mathrm{X}_{2}\right)$, hasil $\left(\mathrm{X}_{3}\right)$ melalui penerapan model pembelajaran learning cycle $(\mathrm{Y})$. 


\section{HASIL dan PEMBAHASAN}

\section{a. Deskripsi Hasil Evaluasi Input, Proses, Hasil}

Penelitian ini menggunakan metode deskriptif kuantitatif, sampel yang digunakan pada penelitian ini adalah mahasiswa semester 5 tahun akademik 2017/2018. Cara yang digunakan dalam pengumpulan data adalah kuesioner/angket dan tes. Pada penelitian ini evaluasi input, proses, hasil diperoleh berdasarkan kuesioner/angket dengan 38 responden mahasiswa. Data hasil kuesioner yang diperoleh dari responden kemudian ditabulasi ke dalam tabel, tabulasi ini dibuat untuk mempermudah perhitungan. Adapun interval nilai berdasarkan hasil kuesioner, sebagai berikut.

Tabel 1. Hasil Interval Nilai Evaluasi Input

\begin{tabular}{cccc}
\hline Interval & Kategori & Frekuensi & $\begin{array}{c}\text { Jumlah } \\
(\boldsymbol{\%})\end{array}$ \\
\hline $39-40$ & Sangat Baik & 4 & 10,52 \\
\hline $37-38$ & Baik & 11 & 28,94 \\
\hline $35-36$ & Cukup Baik & 10 & 26,32 \\
\hline $33-34$ & Sedang & 13 & 34,21 \\
\hline $31-32$ & Kurang & 1 & 2,63 \\
\hline \multicolumn{2}{c}{ Jumlah } & 38 & 100 \\
\hline
\end{tabular}

Hasil interval nilai kuesioner evaluasi input menunjukkan 39 - 40 dengan jumlah 10,52\% sangat baik, 37 - 38 dengan jumlah 28, 94\% baik, 35 - 36 dengan jumlah 26,32\% cukup baik, 33 -34 dengan jumlah $34,21 \%$ sedang, dan 31 - 32 dengan jumlah 2,63\% kurang. Berdasarkan interval nilai tersebut menunjukkan bahwa evaluasi input berjumlah $34,21 \%$ dengan kategori sedang. Artinya hasil tersebut menunjukkan bahwa evaluasi input berdasarkan kuesioner termasuk dalam kategori sedang.

Tabel 2. Hasil Interval Nilai Evaluasi Proses

\begin{tabular}{|c|c|c|c|}
\hline Interval & Kategori & Frekuensi & $\begin{array}{c}\text { Jumlah } \\
(\%)\end{array}$ \\
\hline $49-50$ & Sangat Baik & 5 & 13,15 \\
\hline $47-48$ & Baik & 14 & 36,83 \\
\hline $45-46$ & Cukup Baik & 12 & 31,57 \\
\hline $43-44$ & Sedang & 7 & 18,42 \\
\hline $41-42$ & Kurang & 0 & 0 \\
\hline \multicolumn{2}{|c|}{ Jumlah } & 38 & 100 \\
\hline
\end{tabular}

Hasil interval nilai kuesiner evaluasi proses menunjukkan 49 - 50 dengan jumlah $13,15 \%$ sangat baik, 47 - 48 dengan jumlah 36,83\% baik,
45 - 46 dengan jumlah 31,57\% cukup baik, dan 43 - 44 dengan jumlah 18,42\% sedang. Berdasarkan interval nilai tersebut menunjukkan bahwa evaluasi proses $36,83 \%$ dengan kategori baik. Artinya hasil tersebut menunjukkan bahwa evaluasi proses berdasarkan kuesioner melalui model pembelajaran learning cycle termasuk dalam kategori baik.

Tabel 3. Hasil Interval Nilai Evaluasi Hasil

\begin{tabular}{|c|c|c|c|}
\hline Interval & Kategori & Frekuensi & $\begin{array}{c}\text { Jumlah } \\
(\%)\end{array}$ \\
\hline $48-50$ & Sangat Baik & 5 & 13,15 \\
\hline $45-47$ & Baik & 16 & 42,10 \\
\hline $42-44$ & Cukup Baik & 14 & 36,84 \\
\hline $39-41$ & Sedang & 3 & 7,89 \\
\hline $37-40$ & Kurang & 0 & 0 \\
\hline \multicolumn{2}{|c|}{ Jumlah } & 38 & 100 \\
\hline
\end{tabular}

Hasil interval nilai kuesioner evaluasi hasil menunjukkan 48 - 50 dengan jumlah $13,15 \%$ sangat baik, 45 - 47 dengan jumlah $42,10 \%$ baik, 42 - 44 dengan jumlah $36,84 \%$ cukup baik, dan 39 - 41 dengan jumlah 7,89\% kategori sedang. Berdasarkan interval nilai tersebut menunjukkan bahwa evaluasi hasil $42,10 \%$ dengan kategori baik. Artinya hasil tersebut menunjukkan bahwa evaluasi hasil berdasarkan kuesioner dalam kategori baik.

\section{b. Deskripsi Tes Hasil Belajar dengan Model Pembelajaran Learning Cycle}

Evaluasi ini bertujuan memberikan gambaran objektif dengan menerapkan konsep yang telah dikembangkan terhadap hal-hal yang dievaluasi. Adapun acuan kriteria tes hasil belajar ditentukan berdasarkan rata-rata ideal dan simpangan baku ideal. Adapun rumusnya sebagai berikut.

- Rata-rata ideal (Mi) menggunakan rumus:

Mi $=1 / 2$ (nilai ideal tertinggi+ nilai ideal terendah)

- Standar simpangan baku ideal (Sbi):

Sbi $=1 / 6$ (nilai ideal tertinggi - nilai ideal terendah)

Nilai ideal tertinggi adalah nilai total dari hasil keseluruhan skor pilihan jawaban dari kuesioner, sedangkan nilai ideal terendah adalah nilai total dari keseluruhan skor jawaban terendah dari kuesioner. Adapun hasil pengelompokkan 
dapat dibagi dalam 4 kategori, yaitu:

Tabel 4. Kriteria Penilaian

\begin{tabular}{clc}
\hline No. & \multicolumn{1}{c}{ Nilai } & Kategori \\
\hline 1. & $\mathrm{X} \geq \mathrm{Mi}+1.5 \mathrm{Sbi}$ & Sangat baik \\
\hline 2. & $\mathrm{Mi} \leq \mathrm{X}<\mathrm{Mi}+1.5 \mathrm{Sbi}$ & Baik \\
\hline 3. & $\mathrm{Mi}-1.5 \mathrm{Sbi} \leq \mathrm{X}<\mathrm{Mi}$ & Cukup \\
\hline 4. & $\mathrm{X}<\mathrm{Mi}-1.5 \mathrm{Sbi}$ & Kurang \\
\hline
\end{tabular}

Keterangan:

Mi : 1/2 (nilai ideal tertinggit nilai ideal terendah)

Sbi : simpangan baku skor keseluruhan

$\mathrm{X} \quad$ : skor yang dicapai

Tes hasil belajar ini dilakukan setelah diterapkannya model pembelajaran learning cycle. Jenis tes yang digunakan adalah tes tertulis dalam bentuk esai. Pemberian tes esai didasarkan pada tingkat perkembangan kemampuan kognitif mahasiswa pada mata kuliah evaluasi belajar Geografi. Selain itu, tes ini terdiri dari 10 soal dengan bobot masing-masing skor 1 - 10 dengan skor total jawaban 100. Adapun tes hasil belajar mahasiswa pada ujian akhir semester melalui model pembelajaran learning cycle sebagai berikut.

Tabel 5. Hasil Tes Hasil Belajar

\begin{tabular}{|c|c|c|c|c|c|}
\hline \multicolumn{6}{|c|}{ Descriptive Statistics } \\
\hline & $\mathrm{N}$ & $\begin{array}{l}\text { Mini- } \\
\text { mum }\end{array}$ & $\begin{array}{l}\text { Maxi- } \\
\text { mum }\end{array}$ & Mean & $\begin{array}{c}\text { Std. } \\
\text { Deviation }\end{array}$ \\
\hline tes & 38 & 75,00 & 90,00 & $\begin{array}{c}81,63 \\
16\end{array}$ & 4,56438 \\
\hline $\begin{array}{l}\text { Valid N } \\
\text { (listwise) }\end{array}$ & 38 & & & & \\
\hline
\end{tabular}

Berdasarkan data di atas, total keseluruhan nilai adalah 3102 dengan nilai maksimum dari tes hasil belajar pada ujian akhir semester adalah 90 dan nilai minimum 75 , rata-rata 81,63 dan standar deviasi 4,56. Selanjutnya, hasil tes belajar dimasukkan kedalam kriteria penilaian, hasil yang diperoleh sebagai berikut.

Tabel 6. Kriteria Penilaian

\begin{tabular}{cccc}
\hline No. & Nilai & Frekuensi & Kategori \\
\hline 1 & $\geq 86,25$ & 6 & Sangat baik \\
\hline 2 & $82,5 \leq \mathrm{X}<$ & 13 & Baik \\
& 86,25 & & \\
\hline 3 & $78,75 \leq \mathrm{X}$ & 10 & Cukup \\
\hline
\end{tabular}

\begin{tabular}{llll}
\hline \multicolumn{4}{c}{$<82,5$} \\
\hline 4 & $<78,75$ & 9 & Kurang \\
\hline
\end{tabular}

Pada tabel kriteria penilaian di atas, hasil tes menunjukkan kategori penilaian tes tertulis mahasiswa pada mata kuliah evaluasi belajar Geografi pada kategori baik.

Pengujian dan persyaratan analisis digunakan sebagai penentu terhadap analisis data yang digunakan untuk menguji hipotesis. Uji persyaratan dalam penelitian ini terdiri dari uji normalitas dan uji linearitas. Uji normalitas dilakukan untuk mengetahui keadaan sampel yang diambil apakah berdistribusi normal atau tidak, sedangkan uji linearitas digunakan untuk mengetahui sifat hubungan antara variabel bebas dan variabel terikat linear atau tidak.

\section{Uji Normalitas}

Uji normalitas dilakukan untuk mengetahui distribusi dari penyebaran data dari setiap variabel penelitian. Uji normalitas dalam penelitian ini menggunakan uji kolmogorov-smirnov karena jumlah sampel yang ada > 30 dengan dengan ketentuan apabila nilai $\rho>0,05$ maka data berdistribusi normal.

Tabel 7. Hasil Uji Normalitas Kolmogorofsmirnov

\begin{tabular}{llc}
\hline \multicolumn{2}{c}{ One-Sample Kolmogorov-Smirnov Test } \\
\hline & & $\begin{array}{r}\text { Unstandardi- } \\
\text { zed Residual }\end{array}$ \\
\hline $\mathrm{N}$ & Mean & 0,0000000 \\
\hline Normal Parameters $^{\mathrm{a}}$ & Std. Deviation & 3.88978207 \\
\hline Most Extreme $_{\text {Differences }}$ & Pbsolute & 0,085 \\
\cline { 2 - 3 } & Nesitive & 0,070 \\
\hline Kolmogative & $0,-085$ \\
\hline Asymp. Sig. (2-tailed) & & 0,523 \\
\hline
\end{tabular}

a. Test distribution is Normal.

Berdasarkan hasil di atas diketahui bahwa nilai signifikansi sebesar 0,947 lebih besar dari 0,05, sehingga dapat disimpulkan bahwa data berdistribusi normal. 


\section{Uji Linearitas}

Pengujian linearitas menggunakan kriteria yang digunakan untuk menentukan linearitas data adalah indeks signifikansi linearitas (F linearity) dan indeks penyimpangan linearitas (F deviation from linearity). Apabila indeks signifikansi penyimpangan linearitas $>0,05$ berarti garis regresi linear, dan bila indeks signifikansi linearitas $<0,05$ maka dinyatakan tidak linear. Adapun hasil uji linearitas dapat dilihat pada tabel di bawah ini.

Tabel 8. Hasil Uji Linearitas

\begin{tabular}{cccc}
\hline $\begin{array}{c}\text { Varia- } \\
\text { bel }\end{array}$ & $\begin{array}{c}\text { Signifikansi } \\
\text { linearitas } \\
(\mathrm{F} \\
\text { linearity })\end{array}$ & $\begin{array}{c}\text { Penyimpangan } \\
\text { linearitas } \\
(\mathrm{F} \text { deviation } \\
\text { from linearity })\end{array}$ & Kesimpulan \\
\hline $\mathrm{Y}^{*} \mathrm{X}_{1}$ & 11,451 & 1,353 & Linear \\
\hline $\mathrm{Y}^{*} \mathrm{X}_{2}$ & 2,395 & 1,106 & Linear \\
\hline $\mathrm{Y}^{*} \mathrm{X}_{3}$ & 4,002 & 1,105 & Linear \\
\hline
\end{tabular}

Berdasarkan hasil uji linearitas di atas menunjukkan bahwa nilai indeks signifikansi penyimpangan linearitas lebih besar dari 0,05 maka variabel prediktor $\left(\mathrm{X}_{1}, \mathrm{X}_{2}, \mathrm{X}_{3}\right)$ dengan variabel kriterium $(\mathrm{Y})$ terdapat hubungan linear secara signifikan.

Analisis regresi linear berganda digunakan untuk mengetahui ada tidaknya pengaruh variabel bebas terhadap variabel terikat. Dalam penelitian ini yang dimaksud $\mathrm{X}_{1}$ adalah evaluasi input, $\mathrm{X}_{2}$ proses, dan $\mathrm{X}_{3}$ hasil, sedangkan $\mathrm{Y}$ adalah tes hasil belajar pada ujian akhir semester setelah diterapkannya model pembelajaran learning cycle.

Uji hipotesis yang digunakan adalah uji $\mathrm{F}$ yang berfungsi untuk mengetahui apakah variabelvariabel independen secara simultan berpengaruh signifikan terhadap variabel dependen. Derajat kepercayaan yang digunakan adalah 0,05 . Kriteria pengujiannya jika nilai $F_{\text {hitung }}$ lebih besar dari $F_{\text {tabel }}$ maka hipotesis alternatif $\left(\mathrm{H}_{\mathrm{a}}\right)$ menyatakan bahwa semua variabel independen $(\mathrm{X})$ secara simultan berpengaruh terhadap variabel dependen (Y). Adapun hasil analisis dapat dilihat pada tabel di bawah ini.
Tabel 9. Hasil Regresi Linear Berganda

\begin{tabular}{|c|c|c|c|c|c|}
\hline \multicolumn{6}{|c|}{ ANOVA $^{b}$} \\
\hline Model & $\begin{array}{l}\text { Sum of } \\
\text { Squares }\end{array}$ & $\mathrm{df}$ & $\begin{array}{c}\text { Mean } \\
\text { Square }\end{array}$ & $\mathrm{F}$ & Sig. \\
\hline Regression & 211,017 & 3 & 70,339 & 4,272 & $0,012^{\mathrm{a}}$ \\
\hline Residual & 559,825 & 34 & 16,465 & & \\
\hline Total & 770,842 & 37 & & & \\
\hline $\begin{array}{l}\text { a. Predictors: (C } \\
\text { Proses, Evaluas }\end{array}$ & $\begin{array}{l}\text { nstant), E } \\
\text { nput }\end{array}$ & alua & Hasil, E & raluasi & \\
\hline $\begin{array}{l}\text { b. Dependent V } \\
\text { THB MLC }\end{array}$ & able: & & & & \\
\hline
\end{tabular}

Berdasarkan tabel ANOVA di atas, pengujian secara simultan $X_{1}$ evaluasi input, $X_{2}$ evaluasi proses, $\mathrm{X}_{3}$ evalausi hasil, dan $\mathrm{Y}$ adalah tes hasil belajar pada ujian akhir semester setelah diterapkannya model pembelajaran learning cycle, diperoleh nilai $\mathrm{F}_{\text {hitung }}$ sebesar 4,272 dengan nilai probabilitas (sig.) $=0,012$ dan $\mathrm{F}_{\text {tabel }}$ sebesar 2,86. Dengan demikian nilai $F_{\text {hitung }}=4,272$ lebih besar dari $\mathrm{F}_{\text {tabel=2,86 }}$ maka dapat disimpulkan bahwa varaibel $\mathrm{X}_{1}$ evaluasi input, $\mathrm{X}_{2}$ evaluasi proses, $\mathrm{X}_{3}$ evaluasi hasil secara simultan berpengaruh terhadap variabel terikat $\mathrm{Y}$ yaitu tes hasil belajar pada ujian akhir semester setelah diterapkannya model pembelajaran learning cycle.

Hamzah (2008:139) mengatakan bahwa mengevaluasi adalah proses mengukur dan memulai. Alat ukur adalah instrumen pengukuran yang konkret. Sementara itu, evaluasi terhadap hasil belajar bertujuan untuk mengetahui ketuntasan dalam menguasai kompetensi dasar. Dalam penelitian ini evaluasi input, proses, dan hasil melalui model pembelajaran learning cycle diperoleh hasil penelitian, yaitu; a) evaluasi input, yang meliputi antusiasme, kedisiplinan, sarana dan prasarana, kesiapan tenaga pendidik, dan lingkungan berjumlah $34,21 \%$ dengan kategori sedang. Artinya hasil tersebut menunjukkan bahwa evaluasi input berdasarkan kuesioner termasuk dalam kategori sedang. b) evaluasi proses, yang meliputi engagement (keterlibatan), exspolaration, explanation, elaboration dan evaluation berjumlah $36,83 \%$ dengan kategori baik. Artinya hasil tersebut menunjukkan bahwa evaluasi proses berdasarkan kuesioner melalui model pembelajaran learning cycle termasuk dalam 
kategori baik. c) evaluasi hasil, yang meliputi hasil terbaik pada mata kuliah evaluasi belajar Geografi, dan skor hasil belajar yang diperoleh $>80$ berjumlah $42,10 \%$ dengan kategori baik. Artinya hasil tersebut menunjukkan bahwa evaluasi hasil berdasarkan kuesioner dalam kategori baik.

Tes hasil belajar pada ujian akhir semester dilakukan setelah diterapkannya model pembelajaran learning cycle. Jenis tes yang digunakan adalah tes tertulis dalam bentuk esai. Pemberian tes esai didasarkan pada tingkat perkembangan kemampuan kognitif mahasiswa pada mata kuliah evaluasi belajar Geografi dengan rata-rata 81,63 dan kategori penilaian tes tertulis mahasiswa pada mata kuliah evaluasi belajar Geografi pada kategori baik. Hasil penelitian ini diperkuat dengan pernyataan Weiss dalam Widyoko (2009:5) tujuan evaluasi adalah: "The purpose of evaluation researc $h$ is to measure the effect of program agains the goals it set out accomplish as a means of constributing to subsuquest decision making about the program and improving future programming."

Empat hal yang ditekankan pada rumusan tersebut, yaitu (1) menunjuk pada penggunaan metode penelitian, (2) menekankan pada hasil suatu program, (3) penggunaan kriteria untuk menilai, (4) konstribusi terhadap pengambilan keputusan dan perbaikan program dimasa mendatang. Dengan demikian, hasil dari evaluasi dalam penelitian ini adalah untuk perbaikan program pembelajaran/perkuliahan selanjutnya.

Hasil uji persayatan analisis data pada uji normalitas kolmogorov-smirnov diketahui nilai signifikansi sebesar 0,947 lebih besar dari 0,05, sehingga dapat disimpulkan bahwa data berdistribusi normal. Indeks signifikansi penyimpangan linearitas $>0,05$ maka variabel prediktor $\left(\mathrm{X}_{1}, \mathrm{X}_{2}, \mathrm{X}_{3}\right)$ dengan variabel kriterium $(\mathrm{Y})$ terdapat hubungan linear secara signifikan.

Hasil pengujian secara simultan $X_{1}$ evaluasi input, $\mathrm{X}_{2}$ evaluasi proses, $\mathrm{X}_{3}$ evalausi hasil, dan $\mathrm{Y}$ tes hasil belajar pada ujian akhir semester setelah diterapkannya model pembelajaran learning cycle, diperoleh nilai $\mathrm{F}_{\text {hitung }}$ sebesar 4,272 dengan nilai probabilitas (sig.) $=0,012$ dan $\mathrm{F}_{\text {tabel }}$ sebesar 2,86. Dengan demikian nilai $F_{\text {hitung }}=4,272$ lebih besar dari $\mathrm{F}_{\text {tabel=2,86 }}$ maka dapat disimpulkan bahwa varaibel $X_{1}$ evaluasi input, $X_{2}$ evaluasi proses, $\quad \mathrm{X}_{3}$ evaluasi hasil secara simultan berpengaruh terhadap variabel terikat $\mathrm{Y}$ yaitu tes hasil belajar pada ujian akhir semester setelah diterapkannya model pembelajaran learning cycle

\section{SIMPULAN}

Berdasarkan hasil penelitian dan pembahasan pada bab sebelumnya, dapat disimpulkan sebagai berikut.

1. Evaluasi input, yang meliputi antusiasme, kedisiplinan, sarana dan prasarana, kesiapan tenaga pendidik, dan lingkungan dengan kategori sedang. Evaluasi proses, yang meliputi engagement (keterlibatan), exspolaration, explanation, elaboration dan evaluation melalui model pembelajaran learning cycle dengan kategori baik. Evaluasi hasil, yang meliputi hasil terbaik pada mata kuliah evaluasi belajar Geografi, dan skor hasil belajar yang diperoleh $>80$ dengan kategori baik.

2. Hasil tes belajar pada ujian akhir semester setelah diterapkannya model pembelajaran learning cycle dengan rata-rata 81,63 dan kategori penilaian tes pada kategori baik.

3. Hasil pengujian secara simultan $X_{1}$ evaluasi input, $\mathrm{X}_{2}$ evaluasi proses, $\mathrm{X}_{3}$ evalausi hasil, dan $\mathrm{Y}$ tes hasil belajar pada ujian akhir semester setelah diterapkannya model pembelajaran learning cycle, diperoleh nilai $F_{\text {hitung }}$ sebesar 4,272 dengan nilai probabilitas (sig.) $=0,012$ dan $F_{\text {tabel }}$ sebesar 2,86. Dengan demikian nilai $F_{\text {hitung }}=4,272$ lebih besar dari $\mathrm{F}_{\text {tabel=2,86 }}$ maka dapat disimpulkan bahwa varaibel $\mathrm{X}_{1}$ evaluasi input, $\mathrm{X}_{2}$ evaluasi proses, $\mathrm{X}_{3}$ evaluasi hasil secara simultan berpengaruh terhadap variabel terikat $\mathrm{Y}$ yaitu tes hasil belajar pada ujian akhir semester setelah diterapkannya model pembelajaran learning cycle.

\section{DAFTAR PUSTAKA}

Djemari, Mardapi. 2012. Pengukuran Penilaian dan Evaluasi Pendidikan. Penerbit: Nuha Litera. Yogyakarta 
Dimyati dan Mudjiono. 2009. Belajar dan Pembelajaran. Jakarta: Rineka Cipta. 2008. Teknik Penyusunan Instrumen Tes dan Non Tes. Penerbit: Mitra Cendikia Press, Jogjakarta.

Fraenkel, Jack R. \& Wallen, Norman E. 2009. How to Design and Evaluate Research in Education. San Francisco State University. Seventh Edition.

Hamzah, Uno. 2008. Perencanaan Pembelajaran. Penerbit: Bumi Aksara

Idayati, dkk. 2012. Penerapan Model Pembelajaran Learning Cycle '5E' Untuk Meningkatkan Hasil Belajar Biologi Materi Fotosintesis pada Kelas VIII F SMP Negeri 2 Colomadu Tahun Pelajaran 2011/2012. Naskah Publikasi. FKIP. Universitas Muhammadiyah Surakarta

Margono. 2009. Metodologi Penelitian Pendidikan. Penerbit: Rineka Cipta.

Mertens, Donna M. 2010. Research and Evaluation in Education and Psychology. Third Edition. SAGE.

Riduwan. 2010. Dasar-dasar Statistika. Bandung: Alfabeta.

Sari, Elies Septiana, dkk. 2014. Penerapan Model Pembelajaran Learning Cycle 5E untuk Meningkatkan Aktivitas dan Prestasi Belajar Fisika Siswa kelas X-Keperawatan SMK Kesehatan BIM Probolinggo. Jurnalonline.um.ac.id
Santika, anggit, dkk. 2016. Penerapan Model Pembelajaran Learning Cycle Terhadap Kemmapuan Berpikir Kreatif Siswa Pada Materi Perubahan Lingkungan. Pena ilmiah. Jounal.upi.edu

Slameto. 2010. Belajar dan Faktor-Faktor yang Mempengaruhinya. Jakarta: Rineka Cipta.

Septiana, Elies Sari, Asim, Y. (2006). Penerapan Model Pembelajaran Learning Cycle 5E Untuk Meningkatkan Aktivitas Dan Prestasi Belajar Fisika Siswa Kelas X-Keperawatan SMK Kesehatan BIM Probolinggo.

Sugiyono. 2006. Metode Penelitian Pendidikan: Pendekatan Kuantitatif, Kualitatif, dan $R \quad \& D$. Bandung: Afabeta.

2009. Statistika Untuk Penelitian. Bandung : Alfabeta.

Tarigan, Guntur Henry. 2009. Prinsip-prinsip Dasar Metode Riset Pengajaran dan Pembelajaran Bahasa. Penerbit: Angkasa Bandung.

Widoyoko, Eko Putro. 2009. Evaluasi Program Pembelajaran: Panduan Praktis Bagi Pendidik dan Calon Pendidik. Pustaka Pelajar

2012. Model Pembelajaran Learning Cycle. Tersedia: https://wytr33.wordpress.com /2012/12/25/model-pembelajaran-learning-cycle5e/ diakses 20 Januari 2018 